\title{
Contribution to the Simulation and Parametric Analysis of the Operation of a Solar Concentration Thermal Installation
}

\author{
Mohammed Benramdane ${ }^{1 *}$, Saïd Abboudi ${ }^{2}$, Mea Ghernaout ${ }^{1}$ \\ ${ }^{1}$ ETAP Laboratory, Department of Mechanical Engineering, Faculty of Technology, Tlemcen University, Algeria \\ ${ }^{2}$ ICB-COMM Laboratory - UTBM Website, Belfort Cedex 90010, France
}

Corresponding Author Email: benramdane2006@yahoo.fr

https://doi.org/10.18280/ijht.370210

Received: 27 January 2019

Accepted: 20 May 2019

\section{Keywords:}

solar thermal machine, steam turbine, RANKINE cycle, HIRN cycle, thermodynamic parameters

\begin{abstract}
The objective of this contribution is to highlight the direction of variation in thermal efficiency in order to determine the optimum thermodynamic parameters for the best operation of the solar concentrating heat machine. The machine studied as part of this article works in part following the ideal cycle of RANKINE and other part by following the ideal cycle of HIRN (improved installation).

The preferred approach to achieve the objectives is based on:

- Influence of low pressure and high pressure for a machine working according to the ideal RANKINE cycle.

- And the temperature of overheating for installation next up the ideal cycle of HIRN. Simulations for different modifications on the RANKINE and HIRN cycles show that for an increase in the superheat temperature, the increase of the high pressure and the reduction of the low-pressure lead to a better yield.

This contribution consists, from the simulations, to make a parametric analysis of the operation of an installation in order to propose a possible improvement.
\end{abstract}

\section{INTRODUCTION}

Solar (solar photovoltaic, solar thermal), hydropower, wind, biomass and geothermal energy are inexhaustible flows compared to "stock energies" from fossil fuel deposits in the process of becoming rare: oil, coal, natural gas [1-2].

Therefore, the exploitation of renewable energies is recommended. We are interested in the use of solar energy by solar thermal power plants to meet the energy needs.

The use of solar energy heat in order to produce useful work requires mastery and know-how in two related fields [3-5]:

- Capture and concentration,

- The thermodynamic conversion of the different aspects of energy.

Concentration plants are distinguished, based on their intended use, into solar thermal systems and thermodynamic solar systems. The first allow the absorption and eventually accumulation of thermal energy thanks to a heat transfer fluid, to then be used for industrial or domestic purposes. In the latter, a thermodynamic cycle is added to the incident solar energy collection phase (usually a Stirling cycle or a Rankine cycle) for the transformation of the thermal energy collected into electricity, via an alternator [6-7].

Concerning the costs of the electricity produced, only the initial investment costs and maintenance costs affect them, as solar radiation is exploited as the primary source. In the future, it is expected, however, that they can be further reduced thanks to the entry on the market of an increasing number of suppliers [7-8].

To reduce the dispersion of the reflected light, numerous studies have been carried out on the geometries of a secondary reflective surface to be installed above the tube to re- concentrate the rays [9]. The absorber tube is crossed by molten salts or diathermic oil that heat up, or by water that evaporates producing steam, which is sent into a turbine for the direct production of electricity [7].

This contribution consists, from simulations, in the parametric analysis of the operation of a solar thermal installation, highlighting the direction of the variation of the thermal efficiency as a function of the low and high pressure for a machine working according to the ideal cycle of RANKINE. We were interested to:

- $\quad$ the sense of the variation of the thermal efficiency as a function of the superheat temperature for an improved installation working according to the ideal cycle of HIRN,

- $\quad$ the influence of the overheating temperature for the HIRN cycle and the high and low pressures for both cycles (RANKINE and HIRN), on the yield in order to propose a possible improvement.

Simulations for different modifications on the RANKINE and HIRN cycles show that for an increase in the superheat temperature, the increase of the high pressure and the reduction of the low-pressure lead to a better yield.

\section{WEATHER AND GEOGRAPHICAL CONDITIONS OF THE REGION}

The site considered in this study is located in the western Algerian region, specifically in Tlemcen. The geographic and meteorological parameters of this region are provided below: 


\subsection{Geographic conditions of the region [10]}

Table 1. Geographical data of Tlemcen [11]

\begin{tabular}{|c|c|}
\hline Geographical data & Values \\
\hline Latitude & $35,0^{\circ} \mathrm{N}$ \\
\hline Longitude & $-1,5^{\circ} \mathrm{E}$ \\
\hline Altitude & $806 \mathrm{~m}$ \\
\hline
\end{tabular}

The Wilaya of Tlemcen occupies a position of choice within the national ensemble. It is located on the northwestern coast of the country and has a seafront of $120 \mathrm{~km}$. It is a border wilaya with Morocco, with an area of $9017.69 \mathrm{Km}^{2}$.

\subsection{Weather conditions}

The climate of the Tlemcen region is dry and hot in summer while it is wet and cold in winter. Temperature, relative humidity and solar radiation define its changes. These elements are variable, but a monthly average can be estimated as shown in Table 2 .

Table 2. Meteorological data for Tlemcen

\begin{tabular}{|c|c|c|c|c|c|}
\hline Month & Air Temperature & Relative Humidity & Daily Solar Radiation Horizontal & Atmospheric Pressure & Wind Speed \\
\hline & ${ }^{\circ} \mathrm{C}$ & $\%$ & $\mathrm{kWh} / \mathrm{m}^{2} / \mathrm{j}$ & $\mathrm{kPa}$ & $\mathrm{m} / \mathrm{s}$ \\
\hline January & 10,2 & 73,5 & 2,98 & 98,0 & 1,9 \\
\hline February & 11,2 & 73,9 & 3,92 & 97,9 & 2,0 \\
\hline March & 13,4 & 72,0 & 5,14 & 97,4 & 2,0 \\
\hline April & 15,3 & 66,8 & 6,56 & 97,4 & 2,4 \\
\hline May & 18,4 & 65,7 & 7,15 & 97,5 & 2,4 \\
\hline June & 22,4 & 61,6 & 7,65 & 97,5 & 2,5 \\
\hline July & 25,6 & 58,2 & 7,57 & 97,5 & 2,4 \\
\hline August & 26,1 & 59,2 & 6,89 & 97,5 & 2,3 \\
\hline September & 23,1 & 64,9 & 5,75 & 97,6 & 2,1 \\
\hline October & 19,2 & 69,6 & 4,29 & 97,7 & 1,9 \\
\hline November & 14,8 & 71,7 & 3,14 & & 2,1 \\
\hline December & 11,6 & 73,9 & 2,65 & & 97,9 \\
\hline Annual & 17,6 & 67,5 & 5,31 & 97,6 & 2,1 \\
\hline
\end{tabular}

\section{PRINCIPLE OF A SOLAR POWER PLANT}

The growing importance of solar thermal has led designers to significant progress in their studies (design features). This has been achieved, on the one hand by improving the heat absorption capacity by the solar collector by adding new functionalities to the plate absorber [12] and on the other hand to the improvement of geometry [13] and the use of alternative materials $[2,14,16]$.

\subsection{Principle of operation}

Solar radiation can be focused on a linear or point receiver. The receiver absorbs the energy reflected by the mirror and transfers it to the thermodynamic fluid (Figure 1). This fluid at high temperature and pressure rotates a turbine to obtain mechanical energy, which will subsequently be used for multiple needs (industrial, domestic ...) [17].

For the conversion of solar energy to easily exploitable mechanical energy, we go through two stages:

- Thermo-solar conversion;

- Thermodynamic conversion.

The daily solar cycle is known for its limited duration, hence the need to store the energy obtained for its use in the absence of the source of the latter. In order to increase the performance of solar thermal plants, an auxiliary boiler is often used to raise the temperature of the thermodynamic fluid.

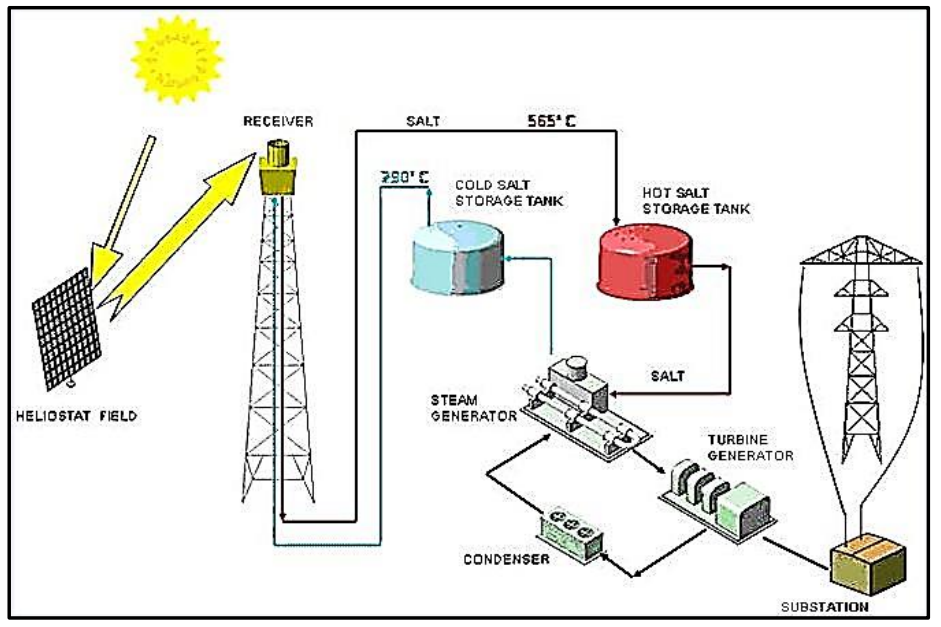

Figure 1. Schematic diagram of a concentrated solar power station [18] 


\section{THERMODYNAMIC CONVERSION}

\subsection{General operation}

The hot source (solar energy) heats (directly or indirectly) the heat transfer fluid which changes from the liquid state to the vapor state. The steam thus produced is admitted into a steam turbine where its expansion causes the wheels of the latter to rotate, coupled to an alternator, the mechanical energy is converted into electrical energy.

Steam condensed in a condenser at the outlet of the turbine (the condensation energy can be used for various needs), it is found in the liquid state. This condensate is returned to the heat transfer fluid system for a new vaporization cycle.

Cogeneration is the joint production of electricity and heat for an industrial process or district heating to improve overall efficiency [18-19].

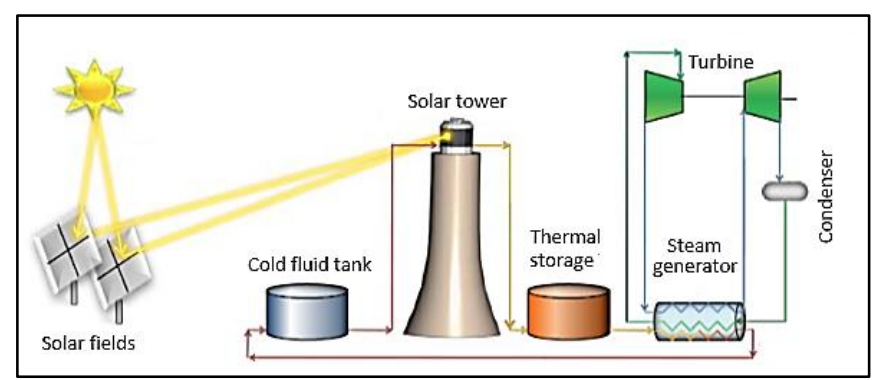

Figure 2. Principle of operation of a concentrated solar thermal power station [19]

\section{STUDY OF THE POWER PLANT}

The plant is composed of two main parts:

- Thermo-solar;

- Steam installation.

\subsection{Study of the thermo-solar part}

Solar thermodynamic plants use a large amount of mirrors that converge the sun's rays to a heat transfer fluid heated at high temperature. To do this, reflective mirrors must follow the movement of the sun to capture and focus radiation throughout the daily solar cycle [20].

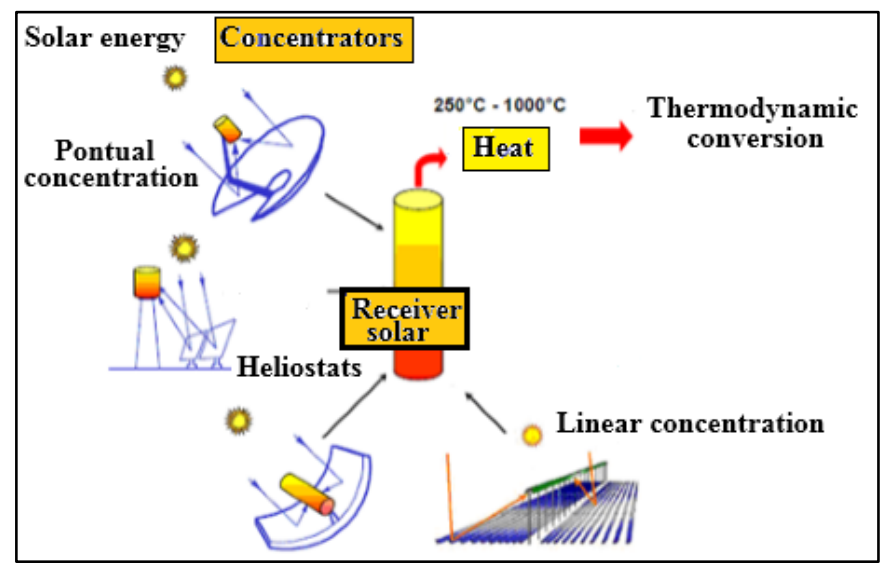

Figure 3. Global diagram of the solar-thermal conversion
In the solar-thermal part, the solar tower installation is chosen because of its high performance. It is composed of a heliostats field chasing the sun along the day and a receiver located in the top of a tower allowing the collection of all the solar rays in a concentrated way.

\section{TRANSPORT AND STORAGE OF HEAT}

Thermal energy is produced in a remote site from where it must be converted into mechanical energy, the latter is continuously transformed into electrical energy. This, in order to transport and store thermal energy for the production to be constant all day to see every month of the year [21].

\subsection{Heat transfer fluids}

The thermal energy from the solar radiation collected is converted by a heat transfer fluid and a second thermodynamic. In some cases, the coolant is used directly as a thermodynamic fluid. The choice of the heat transfer fluid determines the maximum permissible temperature, guides the choice of the technology, the materials of the receiver and conditions the possibility of the convenience of storage.

\subsection{Thermal storage}

The operation of solar power generation systems is strongly constrained by the intermittences of the resource. To remedy this, some thermodynamic plants use thermal storage. This storage rarely reduces costs but considerably increases the value of electricity produced by improving the plant's output. Storage increases the operating time (capacity factor) of the plants compared to the available hours of sunshine, which typically ranges from $20 \%$ without storage to $30-50 \%$ with storage. It is a question of storing and restoring the thermal energy to the required power and at high temperature [21].

The storage capacity is often expressed in hours of production at full load in the absence of solar radiation.

\subsubsection{Storage systems \\ We distinguish the following storage systems:}

\section{$\checkmark$ Systems based on sensible heat [22]}

Systems based on sensible heat in a liquid or gaseous medium are now fairly well controlled. For these technologies, the cost is moderate for a yield greater than $95 \%$. However, this storage technique imposes a temperature variation of the material used between the charge and the discharge of the storage. This disturbs the pressure / temperature stability of the steam loop. Furthermore, the storage of sensible heat in a parabolic trough plant is problematic because the small difference in temperature between the inlet and the outlet of the field (about $100{ }^{\circ} \mathrm{C}$.) imposes storage volumes (and therefore costs). higher than those of tower plants with equivalent capacity.

\section{- Systems based on latent heat [22-23]}

Latent heat storage has two major interests:

- the storage and restitution phases: they are carried out at constant temperature imposed by the material used,

- the volume storage capacities: they are more important than in the case of sensible heat. 
- If the change in liquid-vapor phase has the highest capacities, the excessive volume of vapor produced favors the change of liquid-solid state. Nevertheless this approach is still experimental and still requires further work.

\section{Systems based on thermochemical cycle storage}

This type of storage implements that of energy in the heat of reaction of reversible chemical processes [24]. Its feasibility has been demonstrated in the framework of the European project SOLZINC (2001-2005) concerning the solar carbon reduction of $\mathrm{ZnO}$ for the production of hydrogen.

\subsubsection{Bottle of storage}

A heat transfer fluid storage tank has a thermal storage capacity that varies according to its level of insulation and its physical volume. This type of storage is currently one of the most common ways of storing heat. But this solution is not without side effects [25].

After it has exhausted its energy in the use circuit, the heat transfer fluid returns to the thermal storage tank in its lower part; the fluid is relatively cold compared to that heated in the balloon because it has just lost its heat in the external system. In the balloon, the fluid warms up and goes up gradually where it is extracted to send it back into the circuit of use. However, during this cycle, the cold liquid entering the balloon creates a kind of cold jet that mixes directly with the liquid being heated; this chaotic phenomenon greatly reduces the quality of heat transfer and the entire system performance will be affected accordingly [25-27].

Laminating techniques of the stored fluid improve the distribution of temperatures in the flask, which on the other hand decreases the heat losses due to the mixing phenomenon of the relatively cold fluid coming from the use circuit and the heated one. in the balloon [25].

\section{SIMULATION OPTIMIZATION}

Several optimization methods have been developed over time; some are inspired by the organization in the existing environment while others have been developed to meet the needs of specific scientific areas.

Today, the development of computer tools and simulation software makes it possible to model more and more advanced equipment and systems.

The geometric characteristics of the main balloon (volume and height) are two magnitudes that one seeks to optimize. In general, the procedure provides for variations of the magnitudes to be optimized in order to iteratively determine their values. A system to be optimized must have some freedom in these parameters.

For the purposes of this procedure, the volume of the balloon must be variable. Being cylindrical, its height and volume are directly related. Based on a sample from the thermal storage balloon market, we determined the relation between volume and height for volumes of less than $0.6 \mathrm{~m}^{3}$ by a linear regression equation. For volumes greater than $0.6 \mathrm{~m}^{3}$, the height is given by a relation (1) [28]:

$$
\begin{gathered}
\mathrm{H}_{\mathrm{bln}}=1,737 \cdot \mathrm{V}_{\mathrm{bln}}+1,014 \quad \text { avec } \mathrm{V}_{\mathrm{bln}}<0,6 \mathrm{~m}^{3} \\
\mathrm{H}_{\mathrm{bln}}=\max \left(\min \left(2,2\left(1,78+0,39 \ln \left(\mathrm{V}_{\mathrm{bln}}\right)\right)\right), 1,25\right): \\
\mathrm{V}_{\mathrm{bln}} \geq 0,6 \mathrm{~m}^{3}
\end{gathered}
$$

Or $\mathrm{H}_{\mathrm{bln}}$ is the height of the thermal storage balloon (m), $\mathrm{V}_{\mathrm{bln}}$ is the volume of the balloon $\mathrm{m}^{3}$

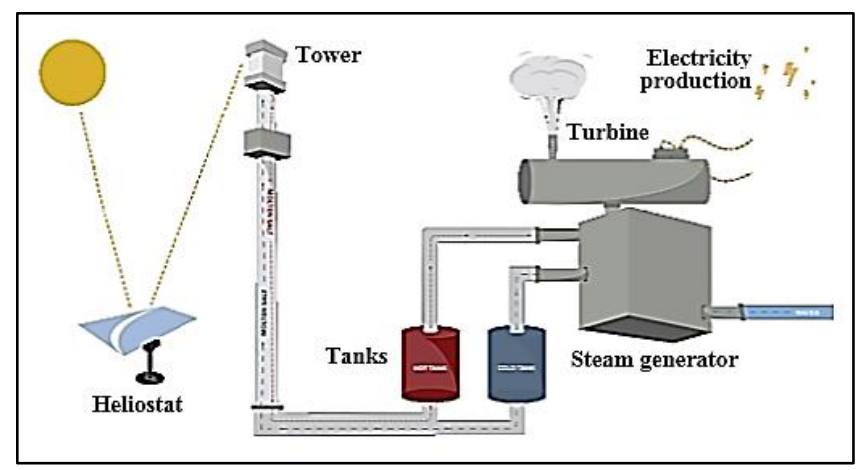

Figure 4. Simplifying diagram of the implementation [20]

\section{THERMODYNAMIC STUDY [29-30]}

The plant is intended for the exploitation of concentrated solar energy, with the aim of converting it into thermal energy, then mechanical energy following a thermodynamic cycle, so that it is finally available for a variety of operations.

Changes have been made on the RANKINE cycle [31-32] of energy implantation to study the thermodynamic parameters, in order to improve the efficiency of the installation, our approach is to add an overheating (HIRN cycle) [33] and see its influence on improving the performance of our machine [34].

\section{- RANKINE cycle [34]}

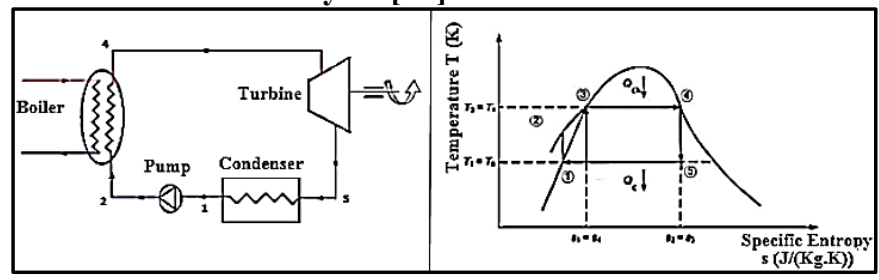

Figure 5. Schematic diagram of the RANKINE cycle

According to the first principle of thermodynamics, the energy balances of each element provide us with the following equation [35]:

$$
\begin{aligned}
& \mathrm{q}_{\mathrm{Ch}}=\mathrm{h}_{4}-\mathrm{h}_{2} \\
& \mathrm{q}_{\mathrm{C}}=\mathrm{h}_{5}-\mathrm{h}_{1} \\
& \mathrm{w}_{\mathrm{P}}=\mathrm{h}_{2}-\mathrm{h}_{1} \\
& \mathrm{w}_{\mathrm{t}}=\mathrm{h}_{4}-\mathrm{h}_{5} \\
& \mathrm{w}_{\mathrm{u}}=\mathrm{w}_{\mathrm{t}}-\mathrm{w}_{\mathrm{P}}=\mathrm{q}_{\mathrm{Ch}}-\mathrm{q}_{\mathrm{C}}
\end{aligned}
$$

The yield is calculated as follows:

$$
\eta=\frac{w_{u}}{q_{C h}}=\frac{q_{C h}-q_{C}}{q_{C h}}
$$

With:

$\mathbf{h}_{\mathbf{i}}$ : Mass enthalpies of the different points, $[\mathrm{kJ} / \mathrm{kg}]$;

$\mathbf{q}_{\mathbf{C h}}$ : Mass boiler heat, [kJ / kg]; 
$\mathbf{q}_{\mathbf{C}}$ : Condenser mass heat, $[\mathrm{kJ} / \mathrm{kg}]$;

$\mathbf{w}_{\mathbf{P}}$ : Pump mass work, [kJ / kg].

By replacing equations (3) and (4) in the expression of the yield, we obtain:

$$
\begin{gathered}
\eta=\frac{\left(\mathrm{h}_{4}-\mathrm{h}_{2}\right)-\left(\mathrm{h}_{5}-\mathrm{h}_{1}\right)}{\mathrm{h}_{4}-\mathrm{h}_{2}} \\
\eta=\frac{\left(\mathrm{h}_{4}-\mathrm{h}_{2}\right)-\left(\mathrm{h}_{5}-\mathrm{h}_{1}\right)}{\mathrm{h}_{4}-\mathrm{h}_{2}+\mathrm{h}_{1}-\mathrm{h}_{1}} \\
\eta=\frac{\left(\mathrm{h}_{4}-\mathrm{h}_{5}\right)-\left(\mathrm{h}_{2}-\mathrm{h}_{1}\right)}{\mathrm{h}_{4}-\mathrm{h}_{1}-\left(\mathrm{h}_{2}-\mathrm{h}_{1}\right)}
\end{gathered}
$$

With:

$$
\mathrm{w}_{\mathrm{P}}=\mathrm{h}_{2}-\mathrm{h}_{1}=\mathrm{v} \cdot \mathrm{dP}
$$

$v$ : Mass volume

This results in the final expression of the output:

$$
\eta=\frac{\mathrm{h}_{4}-\mathrm{h}_{5}-\mathrm{v} \cdot \mathrm{dP}}{\mathrm{h}_{4}-\mathrm{h}_{1}-\mathrm{v} \cdot \mathrm{dP}}
$$

\section{- HIRN cycle [33-35]}

The HIRN cycle operates according to five transformations as shown in the diagrams of Figure 6:

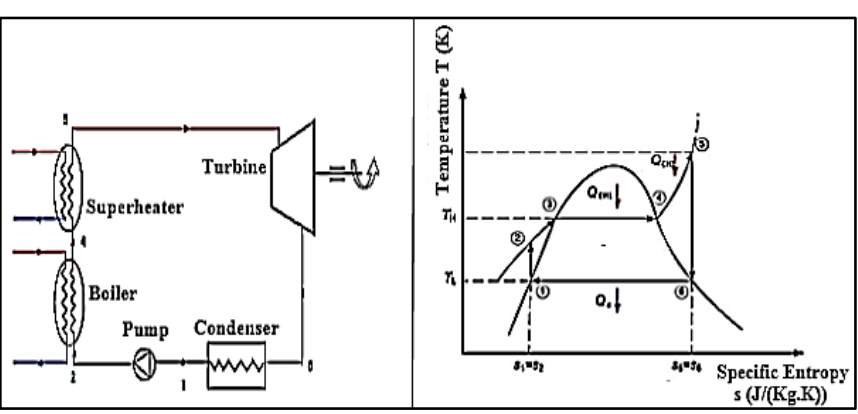

Figure 6. Schematic diagram of the HIRN cycle

According to the first principle of thermodynamics, the energy balance of each element gives us the following equations [34]:

$$
\begin{gathered}
q_{C h 1}=h_{4}-h_{2} \\
q_{C h 2}=h_{5}-h_{4} \\
q_{C h}=q_{C h 1}+q_{C h 2}=h_{5}-h_{2} \\
q_{C}=h_{6}-h_{1} \\
w_{P}=h_{2}-h_{1} \\
w_{t}=h_{5}-h_{6} \\
w_{u}=w_{t}-w_{P}=q_{C h 1}+q_{C h 2}-q_{C}
\end{gathered}
$$

The yield is calculated as follows:

$$
\eta=\frac{w_{u}}{q_{C h}}
$$

By replacing equations (16) and (17) in the expression of the yield, we obtain:

$$
\begin{gathered}
\eta=\frac{h_{5}-h_{2}-\left(h_{6}-h_{1}\right)}{h_{5}-h_{2}} \\
\eta=\frac{h_{5}-h_{2}-\left(h_{6}-h_{1}\right)}{h_{5}-h_{2}+h_{1}-h_{1}} \\
\eta=\frac{h_{5}-h_{6}-\left(h_{2}-h_{1}\right)}{h_{5}-h_{1}-\left(h_{2}-h_{1}\right)}
\end{gathered}
$$

With:

$$
\mathrm{w}_{\mathrm{P}}=\mathrm{h}_{2}-\mathrm{h}_{1}=\mathrm{v} \cdot \mathrm{dP}
$$

$v$ : Mass volume.

This results in the final expression of the output:

$$
\eta=\frac{h_{5}-h_{6}-v \cdot d P}{h_{5}-h_{1}-v \cdot d P}
$$

Our contribution is primarily to study the influence of pressure on the performance of the installation and then to vary the temperature of overheating to evaluate its effects.

Two methods can be used to calculate the various thermodynamic parameters: $\mathrm{T}, \mathrm{P}, \mathrm{v}, \mathrm{h}$ and $\mathrm{s}$ :

- Graphical method: use of Mollier (h, s), Clapeyron (P, v) and enthalpic $(T, h)$ diagrams;

- Analytical method: use of thermodynamic properties tables of liquid water, saturated liquid, wet, saturated steam and superheated steam.

We privileged to work with the tables of the thermodynamic parameters (analytical method) for their precision.

\section{Working hypotheses}

The choice of working pressure varies between:

- 1 to 7 bar for low pressure,

- 10 to 30 bar for high pressure

- the temperature of overheating varies between 200 and $540{ }^{\circ} \mathrm{C}$

The temperature range is required, by the configuration of the solar concentration facility; whereas the pressure margin depends essentially on the capacities of the elements of the thermodynamic installation. To reduce both the investment costs and the complexity of the installation; we choose simple and efficient equipment that satisfies the pressure requirements mentioned previously, replacing the technological components of the installation (pump and turbine) with large morphologies and high costs.

\section{Parameter calculation mode}

\section{- For the RANKINE cycle}

The different thermodynamic parameters of each point in the RANKINE cycle are determined; these parameters are tabulated in the thermodynamic tables of the water for the resolution of the yield equation (13).

Let us treat the cycle operating with 2 bars as low pressure and 10 bars as high pressure, as shown in the Figure 8 . 


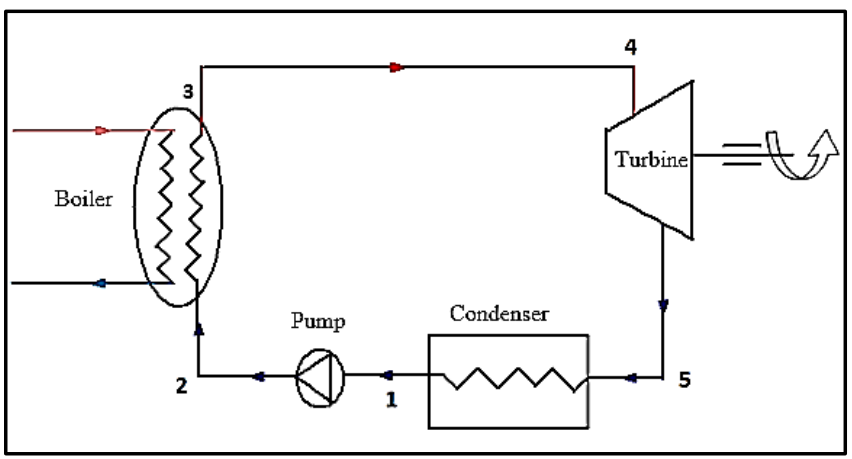

Figure 7. Schematic diagram of the RANKINE cycle

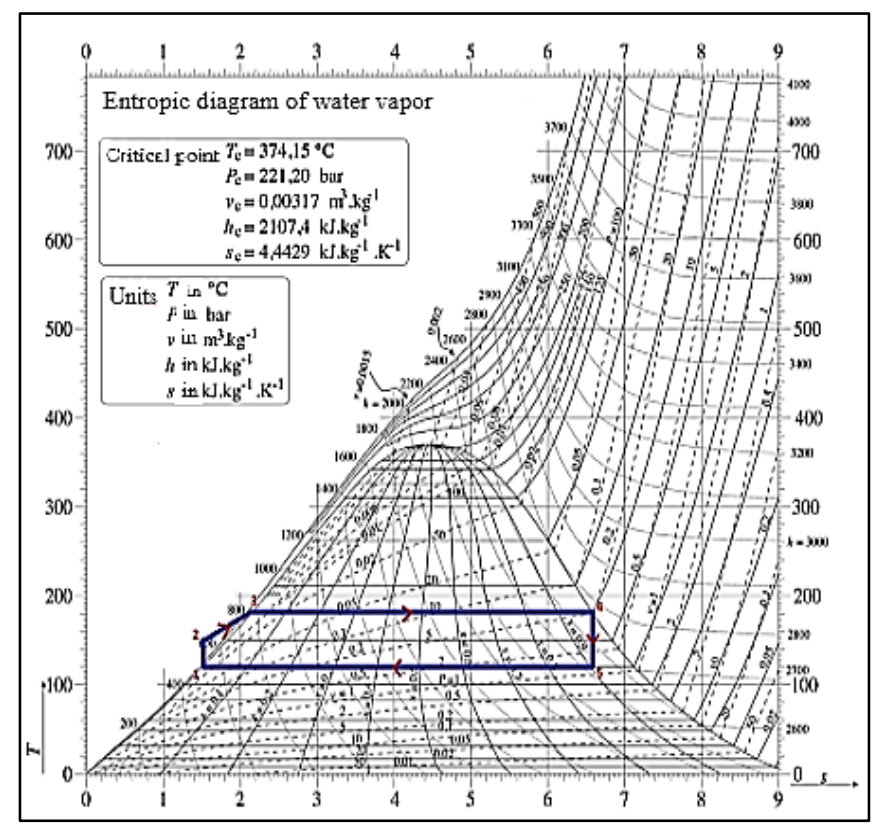

Figure 8. RANKINE cycle between 2 and 10 bar

\section{Point 1:}

$$
\left\{\begin{array} { c } 
{ \mathrm { P } _ { 1 } = 2 \text { bars } } \\
{ \mathrm { x } _ { 1 } = 0 }
\end{array} \stackrel { \text { From T.V.S } } { \longrightarrow } \left\{\begin{array}{c}
\mathrm{T}_{1}=120,2{ }^{\circ} \mathrm{C} \\
\mathrm{h}_{1}=504,7 \mathrm{~kJ} / \mathrm{kg} \\
\mathrm{v}_{1}=1,060510^{-3} \mathrm{~m}^{3} / \mathrm{kg} \\
\mathrm{s}_{1}=1,5301 \mathrm{~kJ} /(\mathrm{kg} . \mathrm{K})
\end{array}\right.\right.
$$

Point 2:

$$
\left\{\begin{array}{c}
P_{2}=10 \text { bars } \\
s_{1}=s_{2}=1,5301 \mathrm{~kJ} /(\mathrm{kg} . \mathrm{K})
\end{array}\right.
$$

Point 3:

$$
\left\{\begin{array} { c } 
{ \mathrm { P } _ { 3 } = 1 0 \text { bars } } \\
{ \mathrm { x } _ { 3 } = 0 }
\end{array} \stackrel { \text { From T.V.S } } { \longrightarrow } \left\{\begin{array}{c}
\mathrm{T}_{3}=179,9^{\circ} \mathrm{C} \\
\mathrm{h}_{3}=762,81 \mathrm{~kJ} / \mathrm{kg} \\
\mathrm{s}_{3}=2,1387 \mathrm{~kJ} /(\mathrm{kg} . \mathrm{K})
\end{array}\right.\right.
$$

\section{Point 4:}

$$
\left\{\begin{array} { l } 
{ \mathrm { P } _ { 4 } = 1 0 \text { bars } } \\
{ \mathrm { T } _ { 4 } = 1 7 9 , 9 ^ { \circ } \mathrm { C } }
\end{array} \stackrel { \text { From T.V.S } } { = } \left\{\begin{array}{c}
\mathrm{h}_{4}=2778,1 \mathrm{~kJ} / \mathrm{kg} \\
\mathrm{s}_{4}=6,5863 \mathrm{~kJ} /(\mathrm{kg} . \mathrm{K})
\end{array}\right.\right.
$$

\section{Point 5:}

$$
\left\{\begin{array}{c}
\mathrm{P}_{5}=2 \text { bars } \\
\mathrm{T}_{5}=120,2^{\circ} \mathrm{C} \\
\mathrm{s}_{5}=\mathrm{s}_{4}=6,5863 \mathrm{~kJ} /(\mathrm{kg} . \mathrm{K})
\end{array}\right.
$$

Calculation of $\mathrm{x}_{5}$ to calculate $\mathrm{h}_{5}$ :

$$
x_{5}=\frac{s_{5}-s_{1}}{s_{v}-s_{1}}
$$

With

$\mathrm{S}_{\mathrm{v}}=7,1271 \mathrm{~kJ} /(\mathrm{kg} . \mathrm{K})$ : entropy of saturated steam

AN:

$$
\begin{aligned}
x_{5}= & \frac{6,5863-1,5301}{7,1271-1,5301} \\
& x_{5}=0,9034 \\
h_{5}= & x_{5}\left(h_{v}-h_{1}\right)+h_{1},
\end{aligned}
$$

With

$\mathrm{h}_{\mathrm{v}}=2201,9 \mathrm{~kJ} / \mathrm{kg}$ : saturated vapor enthalpy

AN:

$$
\begin{gathered}
h_{5}=0,9034(2201,9-504,7)+504,7 \\
h_{5}=2493,9428 \mathrm{~kJ} / \mathrm{kg}
\end{gathered}
$$

Performance calculation:

$$
\eta=\frac{h_{4}-h_{5}-v \cdot d P}{h_{4}-h_{1}-v \cdot d P}
$$

AN:

$$
\begin{gathered}
\eta=\frac{(2778,1-2493,9428) \cdot 10^{3}-1,0605 \cdot 10^{-3} \cdot(10-2) \cdot 10^{5}}{(2778,1-504,7) \cdot 10^{3}-1,0605 \cdot 10^{-3} \cdot(10-2) \cdot 10^{5}} \\
\eta=12,4 \%
\end{gathered}
$$

\section{- For the HIRN cycle}

By the same method as the RANKINE cycle, the different thermodynamic parameters of each point in the HIRN cycle are determined; these parameters are tabulated in the thermodynamic tables of water for the resolution of the equation of yield (24).

For example, let us treat the cycle operating with 2 bars as low pressure and 10 bars as high pressure at a temperature of overheating of $400{ }^{\circ} \mathrm{C}$, Figure (10).

By the same method of RANKINE, the parameters of the various points and the yield are calculated:

$$
\eta=\frac{\left(h_{5}-h_{6}\right)-v \cdot d P}{\left(h_{5}-h_{1}\right)-v \cdot d P}
$$

AN:

$$
\begin{gathered}
\eta=\frac{(3263,9-2986) \cdot 10^{3}-1,0605 \cdot 10^{-3} \cdot(10-2) \cdot 10^{5}}{(3263,9-504,7) \cdot 10^{3}-1,0605 \cdot 10^{-3} \cdot(10-2) \cdot 10^{5}} \\
\eta=15,2 \%
\end{gathered}
$$

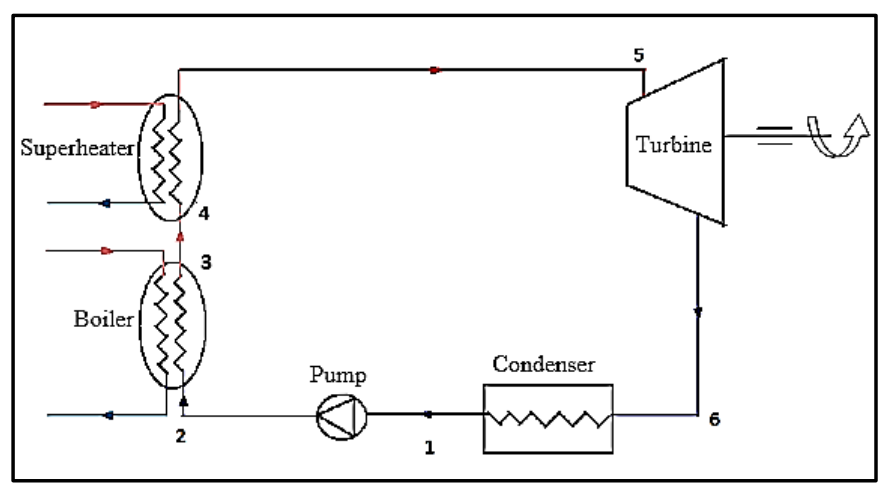

Figure 9. Schematic diagram of the HIRN cycle 


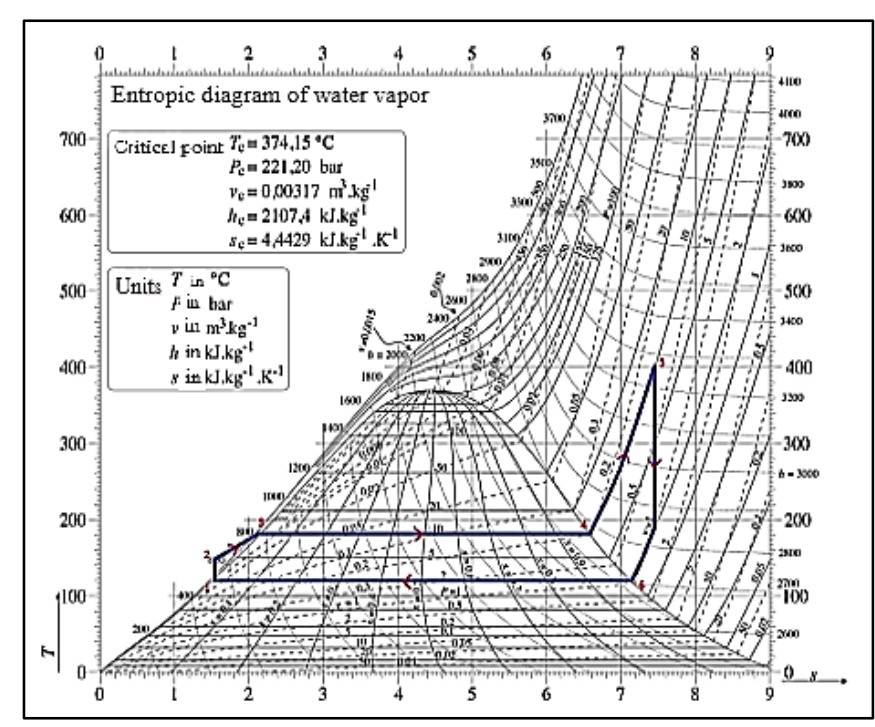

Figure 10. HIRN cycle between 2 and 10 bar at $400{ }^{\circ} \mathrm{C}$

\section{SIMULATION}

\subsection{Work constraints}

\subsubsection{High pressure}

The pressure of the boiler, which is that of the pump outlet, is taken equal to the saturation pressure of the liquid solution at the evaporation temperature.

\subsubsection{Low pressure}

The low pressure in the condenser, which is that of the outlet of the turbine, is equal to the saturation pressure of the fluid at the condensation temperature.

\subsubsection{Temperatures}

The boiler and the high-pressure superheater are supplied in parallel, by a single source of heat, which is none other than concentrated solar energy.

\subsection{Simulation of the RANKINE cycle}

- Constant $\mathrm{P}_{\mathrm{H}}$ :

To study the influence of the low pressure in the RANKINE cycle on its efficiency, we keep a constant high pressure and we vary the low pressures, by the same calculation method quoted in the previous example, the results are illustrated by curves below:

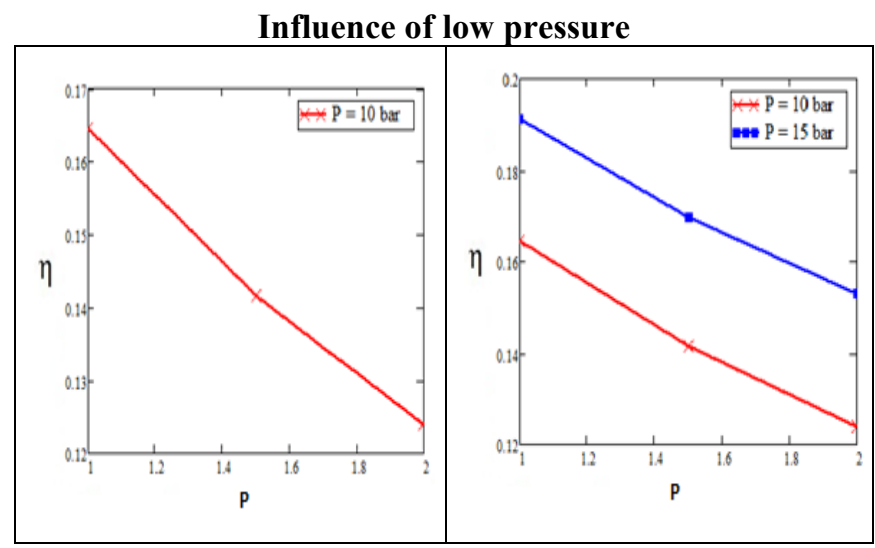

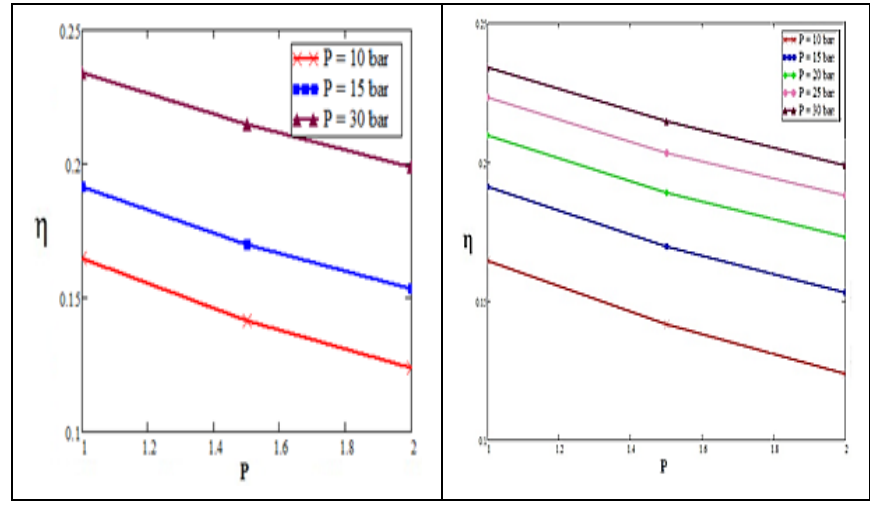

Figure 11. Variation of the yield as a function of the low pressures for different high pressures

- Constant $\mathrm{P}_{\mathrm{B}}$ :

To study the influence of the high pressure in the RANKINE cycle, on its efficiency, we keep a constant high pressure and we vary the high pressures, by the same method of calculation quoted in the preceding example, the results are illustrated by curves below:

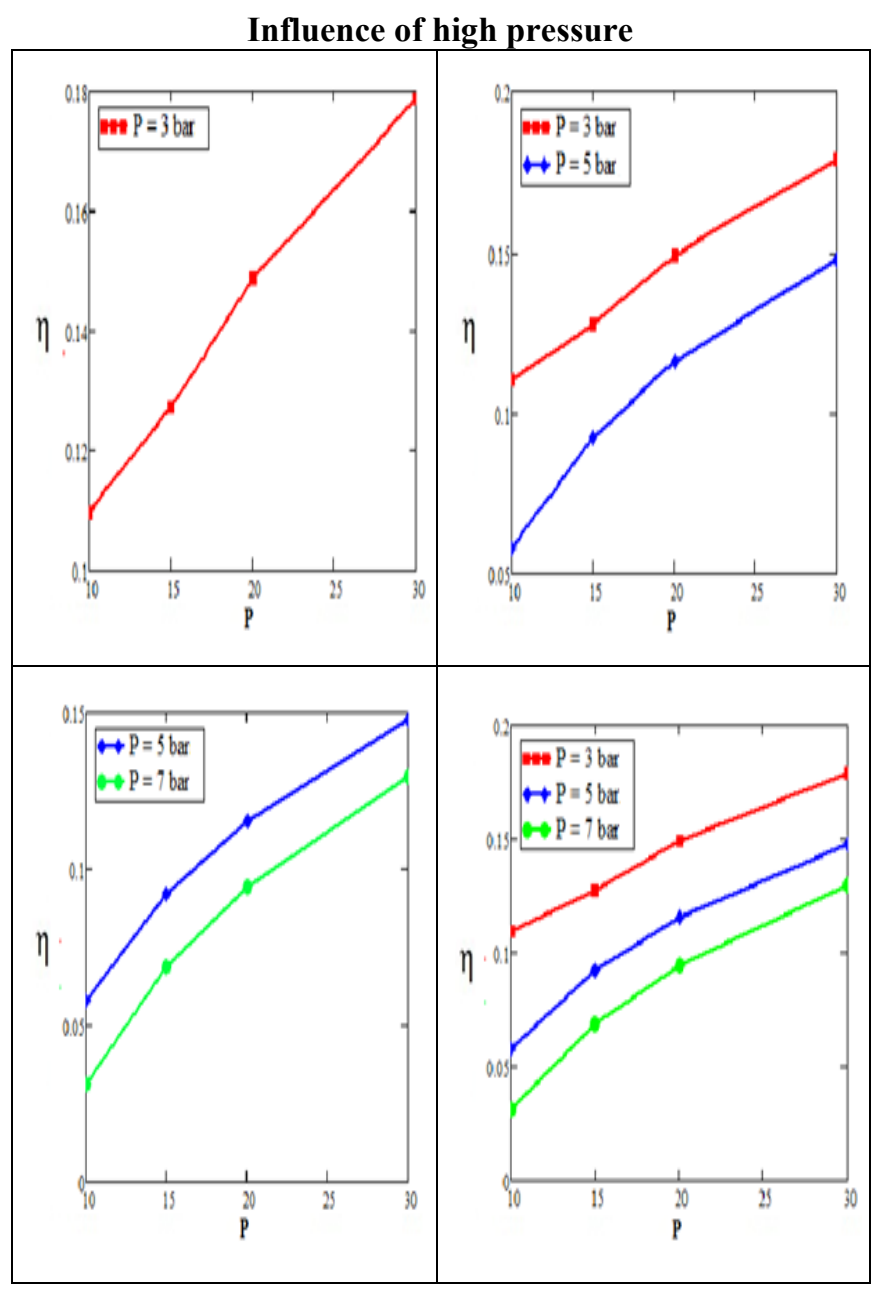

Figure 12. Variation of the yield according to the high pressures for different low pressure

\subsection{Simulation of the HIRN cycle (temperature variation)}

To study the influence of the low pressure as well as that of the overheating temperature in the HIRN cycle on its efficiency, the high pressure is fixed and the low pressures and 
the temperature of overheating are varied, using the same method of calculation presented in the calculation example (HIRN cycle), the results are illustrated by the curves below:

\subsubsection{Influence of low pressure $\left(\mathrm{P}_{\mathrm{B}}\right)$}

- Constant $\mathrm{P}_{\mathrm{H}}$ :

To study the influence of the high pressure as well as that of the superheating temperature in the HIRN cycle, on its efficiency, a constant low pressure is maintained and varying the high pressure and the temperature of overheating, the results are illustrated by curves below:

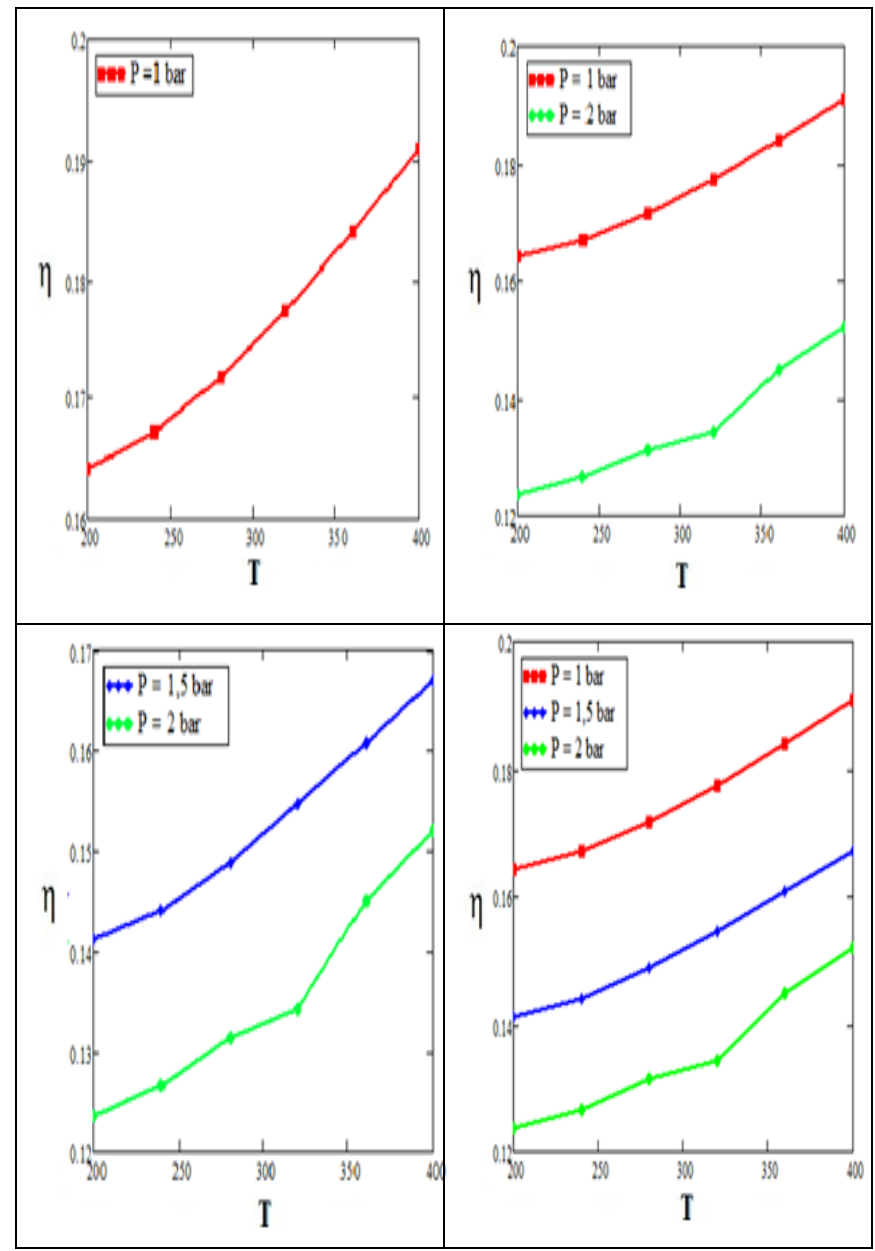

\section{a. For $\mathbf{P}_{\mathbf{H}}=10$ bar}

Figure 13. Variation of the yield as a function of the temperatures for different low pressure $\left(\mathrm{P}_{\mathrm{H}}=10 \mathrm{bar}\right)$

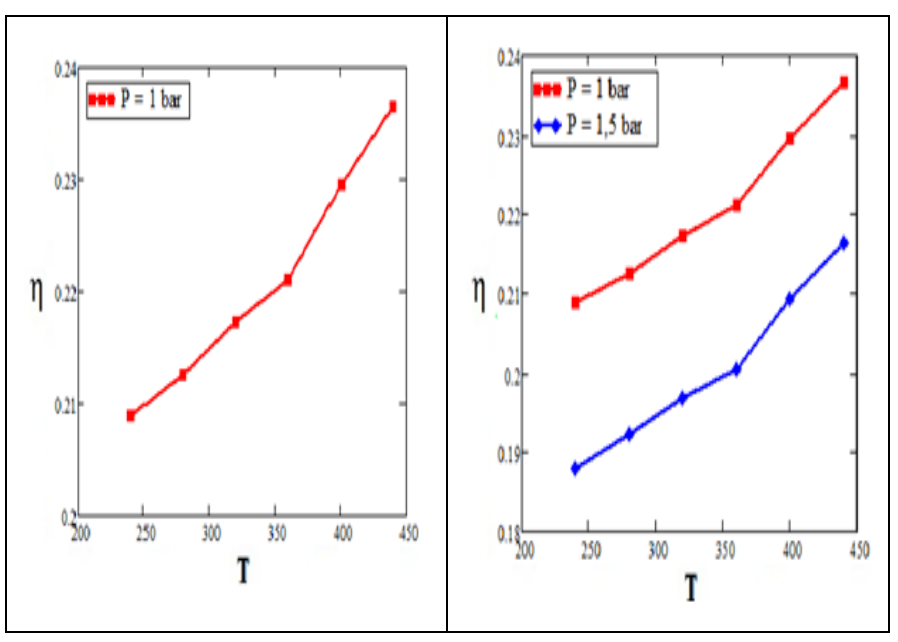

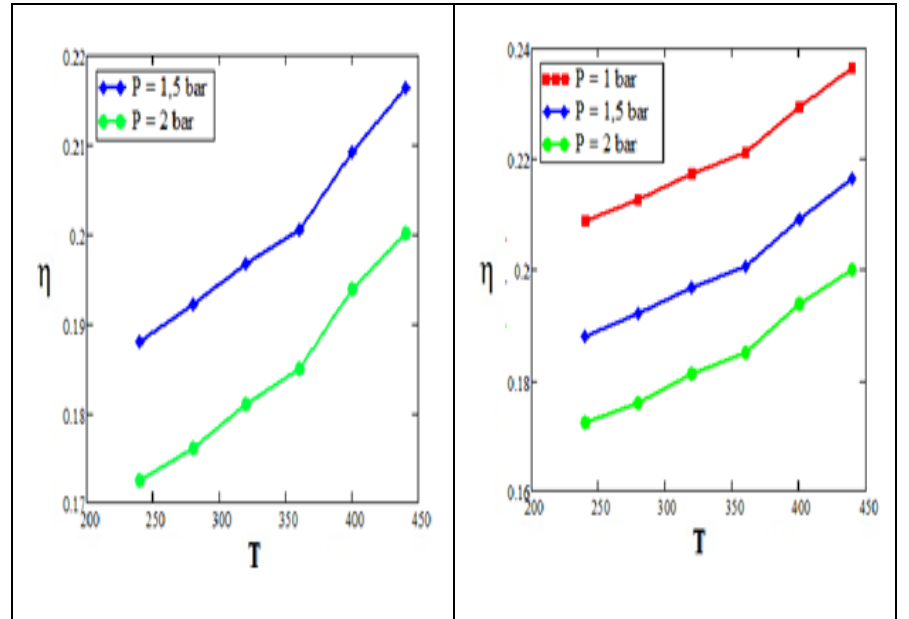

b. For $\mathbf{P}_{\mathrm{H}}=20$ bar

Figure 14. Variation of the yield as a function of the temperatures for different low pressure $\left(\mathrm{P}_{\mathrm{H}}=20 \mathrm{bar}\right)$

- Constant $\mathrm{P}_{\mathrm{B}}$ :

To study the influence of the high pressure as well as that of the superheating temperature in the HIRN cycle, on its efficiency, a constant low pressure is maintained and varying the high pressure and the temperature of overheating, the results are illustrated by curves below:

\subsubsection{Influence of high pressure}

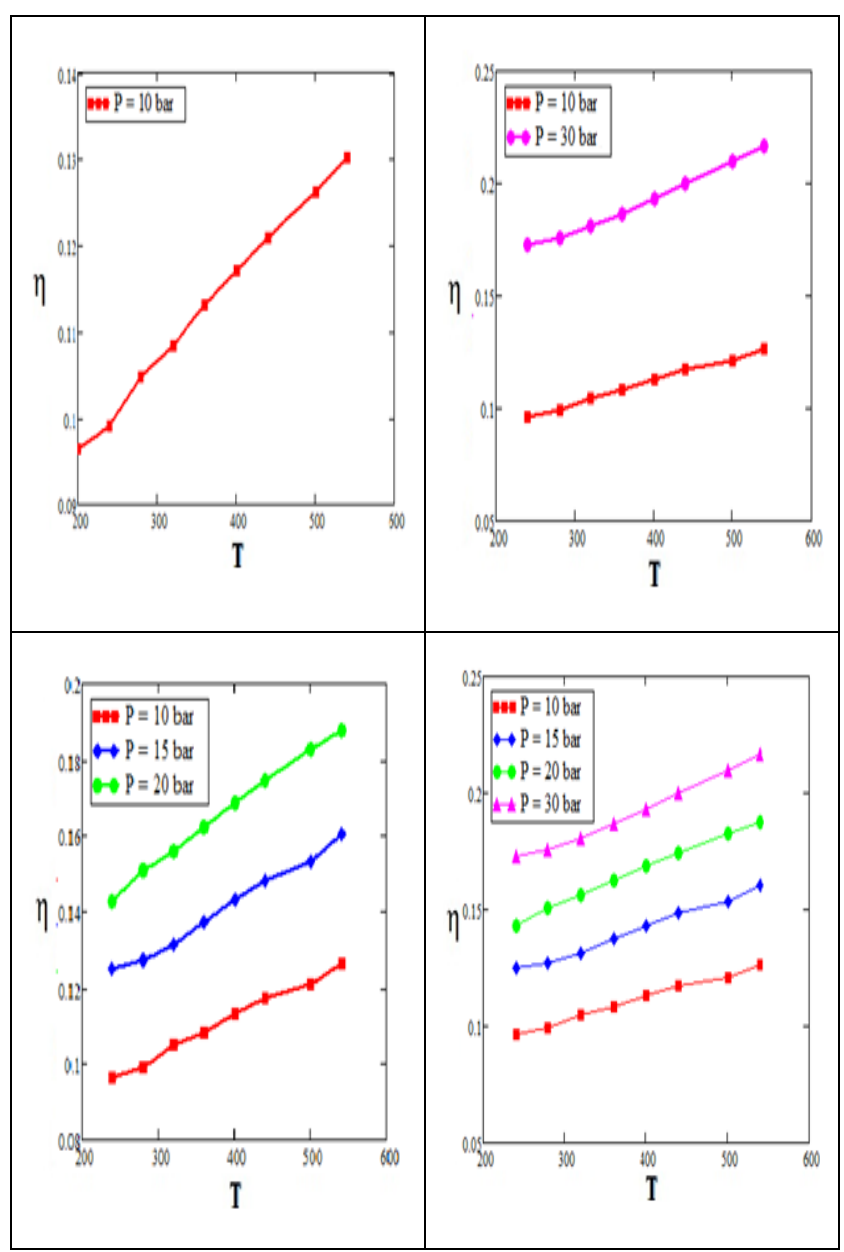

a. $\quad$ For $P_{B}=3$ bar

Figure 15. Variation of the yield as a function of the temperatures for different high pressures $\left(\mathrm{P}_{\mathrm{B}}=3 \mathrm{bar}\right)$ 


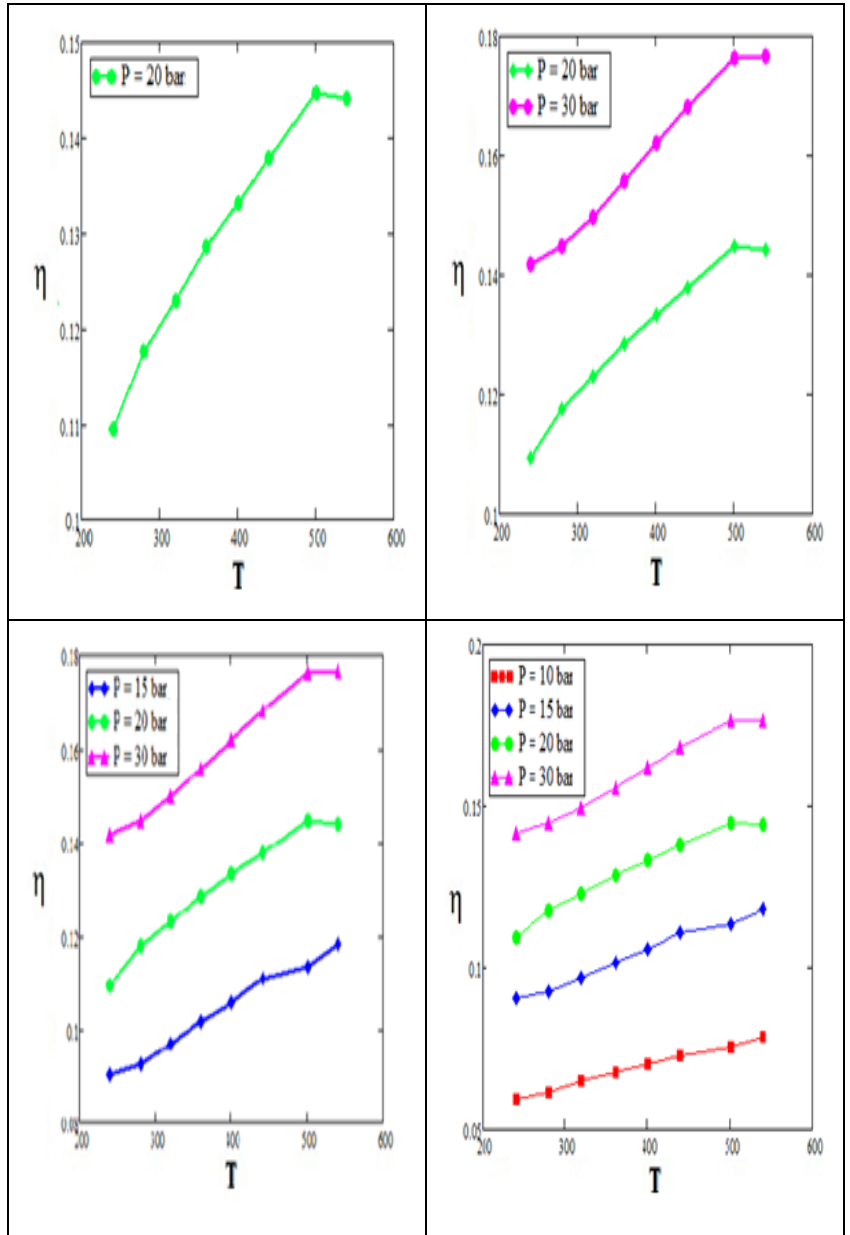

b. $\quad$ For $\mathbf{P}_{B}=5$ bar

Figure 16. Variation of the yield as a function of the different high-pressure temperatures

$$
\left(\mathrm{P}_{\mathrm{B}}=5 \text { bar }\right)
$$

\subsection{Interpretation of graphs}

\subsubsection{RANKINE cycle}

Figures (11) and (12) show the variation of the yield as a function of the pressures. The first part (Figure (11)) consists in studying the influence of the choice of the low pressure on the performances of the RANKINE cycle, whereas the second part (Figure (12)) shows the effect of the choice of the high pressure on the performance of the latter. To clarify and value our results we have established our study with several constant values for the high pressure in the first part and the low pressure in the last one.

\section{* In the first analysis}

Figure (11), we chose a high pressure of 10 bar to see the influence of the low pressure (it was varied from 1 to 2 bars). We have noticed that with the increase of the latter, the return evolves inversely.

The same analysis with the values 15, 20, 25 and 30 bar, allowed us to note the same results, the yield is inversely proportional to the variation of the low pressure. By comparing the graphs obtained between them, we notice that at higher pressures, the yield tends to rise. The graphs in Figure (11) allowed us to compare each yield with all the others according to the low pressures chosen for the study.

Figure (12) illustrates the appearance of the effect of high pressure on the efficiency of the RANKINE cycle, which prompted us to make the second analysis: the influence of high pressure on thermodynamic performance.

\section{* In the second analysis}

As seen previously, and from the results, we confirmed what we noticed before; the evolution of the yield is directly proportional to the variation of the high pressure.

To draw the graph of Figure (12) and deduce the previous result was set a value of the low pressure at 3 bar with the variation of the high pressure from 10 to 20 bar.

For confirmation, other values of the low pressure have been chosen, the results being identical after comparison between the graphs of the Figure (12). It can be seen that the two analysis parts of the RANKINE cycle are coherent with each other. The latter confirms the first. The graphs show the decrease of the thermodynamic efficiency at the increase of the low pressure.

\subsubsection{HIRN cycle}

Figures (13) to (16) show the direction of the variation of the thermal efficiency as a function of the temperature of the superheat for an installation working according to the improved cycle of HIRN (cycle with overheating).

Our study consists in studying the influence of the low pressure and the high pressure as a function of the overheating temperature on the performances of the HIRN cycle. Systematically, our work is divided into two parts.

\section{* In the first part}

We chose a fixed value of the high pressure at 10 bar. The superheat temperature was varied from 200 to $400{ }^{\circ} \mathrm{C}$ following three values of the low pressure 1, 1.5 and 2 bar as illustrated by Figures (13) and (14).

The results presented in the graphs of Figure (13) clearly show the evolution of the yield as a function of the overheating temperature. The higher the temperature, the better the cycle.

The graphs in Figure (14) enrich our study; they show and compare between yields for different values of low pressure. We notice that with the increase of the low pressure the yield is decreasing. This result is similar to that obtained for the theoretical RANKINE cycle.

For more validity, we enriched our study with other fixed value of the high pressure $\mathrm{P}=20$ bars. The results shown in Figure (14) show an analogy after following the same steps. The evolution of the yield is proportional to the variation of the temperature of overheating and inversely proportional to the variation of the low pressure.

\section{* The second part}

It consists in studying the influence of the choice of the high pressure on the performances of our installation according to the temperature of overheating.

We chose a fixed value of the low pressure 3 bars, we varied the high pressure from 10 to 30 bars, after simulation, we see the evolution of the graphs shown in the figures, depending on the temperature of overheating. We see that the efficiency is proportional with the temperature of overheating.

After having established the same analyzes with other values of the low pressure the result is confirmed. The graphs of Figures (15) and (16) include and show the influence of high pressure on the performance of the installation, it is deduced whereas the higher the high pressure and the higher the yield is increasing.

We note in the graphs shown in Figures (16), that at high 
pressures of 20 and 30 bar with the low pressure of 5 bar, the yield reaches a peak operating from the temperature of $500^{\circ}$ $\mathrm{C}$; this is because the cycle reaches a maximum in performance after consuming a heat rate. Then any addition in heat will remain useless and will not increase the yield under any circumstances.

\section{CONCLUSION}

This work consisted in modifying the solar concentration thermal installation and changing the thermodynamic parameters in order to study their influence on the efficiency of this installation both following the RANKINE cycle and following that of HIRN.

The parametric analysis of the operation of the installation by highlighting the direction of the variation of the thermal efficiency as a function of the low and high pressure for a machine working according to the two cycles gave us the following results:

- In the RANKINE cycle, after simulating several cases of pressure evolution (low and high pressure), we conclude that:

a- the efficiency is directly proportional with the increase of the high pressure whereas it is inversely proportional with the elevation of the low pressure.

b- depending on the pressure difference or when increasing the pressure ratio, the performance is better.

In addition, it is proposed to increase the compression and expansion ratio in the next thermodynamic installations, within the technical and economic limits.

In the HIRN cycle, we studied the influence of the two thermodynamic parameters (temperature and pressure). After having simulated with several changes concerning the temperature of overheating, the low and high pressure, the results were similar to those found previously:

a- The efficiency and directly proportional to the increase of the temperature of overheating,

b- It is also for the high pressure and it is inversely proportional with the elevation of the low pressure.

Our suggestions for future thermodynamic implantations are to increase the compression and expansion ratio as well as to raise the temperature of overheating within the operating limits.

In order to perfect the operation of a solar thermal installation and in the case where the investment and quite expensive, we can afford to add another turbine, after they are heated at the exit of the first turbine (HIRN with reheat) which relaxes the vapors. This will allow us to extract more useful work, without reaching very high temperatures that increase the risk of damaging turbines, in other words, reducing the life of the turbines and the incessant demand for maintenance.

More tests, examinations and specifically advanced studies can be done to verify and clarify the behavior of thermal performance after the design of such geometric changes on the thermodynamic installation, as well as other writings of economic, financial, ecological interests. and environmental will have the opportunity to be updated in order to better understand the usefulness of such achievable improvements on the operating systems of solar energy in particular and all renewable energy easily and abundantly exploitable in general.

This work provides a global idea of concentrated solar power plants, through the years and its evolution through the centuries.

The coming decades will more than likely see the creation of a large number of Fresnel, parabolic, parabolic, and solar tower concentrators. The costs will be remarkably reduced and it is possible that government incentives for such systems become usefully solicited.

In the medium and long term, concentrating systems will contribute significantly to the objectives of reducing $\mathrm{CO}_{2}$ emissions and the development and energy supply problems of deserted regions.

\section{REFERENCES}

[1] The 2014 renewable energy barometer 5th edition produced and edited by Observ'ER, 5th edition.

[2] Sylvain, Q. (2007). Concentrated Solar Power Plants. University of Liège, Faculty of Applied Sciences, pp. 318.

[3] Hakim, S. (2017). Search for an optimal configuration of a solar stack plant. PhD Thesis.

[4] Daher, D.H. (2017). Modeling and experimental analysis of a photovoltaic solar power station in a desert maritime environment. PhD. Thesis. University of Lyon, French.

[5] Hoseinia, H., Mehdipourb, R. (2018). Evaluation of solar-chimney power plants with multiple-angle collectors. Journal of Computational and Applied Research in Mechanical Engineering, 8(1): 85-96. https://doi.org/10.22061/JCARME.2017.2282.1213

[6] Dellicompagni, P., Franco, J. (2019). Potential uses of a prototype linear Fresnel concentration system. Renewable Energy, 136: 1044-1054. https://doi.org/10.1016/j.renene.2018.10.005

[7] Cucumo, M.A., Ferraro, V., Kaliakatsos, D., Nicoletti, F. (2019). Solar tracking system for a linear Fresnel plant with two degrees of freedom reflectors. TECNICA ITALIANA-Italian Journal of Engineering Science, 63(2-4): 143-150. https://doi.org/10.18280/ti-ijes.632405

[8] Gabbrielli, R., Castrataro, P., Medico, F.D., Palo, M.D., Lenzo, B. (2014). Levelized cost of heat for linear Fresnel concentrated solar systems. Energy Procedia, 49: 1340-1349. https://doi.org/10.1016/j.egypro.2014.03.143

[9] Facão, J., Oliveira, A.C. (2011). Numerical simulation of a trapezoidal cavity receiver for a linear Fresnel solar collector concentrator. Renewable Energy, 36: 90-96. https://doi.org/10.1016/j.renene.2010.06.003

[10] National Agency for Investment Development (ANDI) 2015.

[11] Tyner, C., Wasyluk, D. (2014). eSolar's modular, scalable molten salt power tower reference plant design. Energy Procedia, 49: 1563-1572. https://doi.org/10.1016/j.egypro.2014.03.165

[12] Alshamaileh, E. (2010). Testing of a new solar coating for solar water heating applications. Solar Energy, 84(9): 1637-1643.

https://doi.org/10.1016/j.solener.2010.06.003

[13] Tanaka, H. (2011). Solar thermal collector augmented by flat plate booster reflector optimum inclination of 
collector and reflector. Appl Energy, 88(4): 1395-404. https://doi.org/10.1016/j.apenergy.2010.10.032

[14] Ruelas, J., Sauceda, D., Vargas, J., García, R. (2018). Thermal and concentration performance for a wide range of available offset dish solar concentrators. Applied Thermal Engineering, 144(5): 13-20. https://doi.org/10.1016/j.applthermaleng.2018.08.028

[15] Carlsson, B., Persson, H., Meir, M., Rekstad, J.A. (2014). A total cost perspective on use of polymeric materials in solar collectors-importance of environmental performance on suitability. Appl Energy, 125: 10-20. https://doi.org/10.1016/j.apenergy.2014.03.027

[16] Dahmani, M., Adouane, B., Ferahta, F.Z., Aouachria, Z. (2017). Mathematical modelling and optimisation of a solar collector performances. Journal of New Technology and Materials JNTM, 7(1): 83-89. https://doi.org/10.12816/0044040

[17] Nadia, B. (2013). Contribution to the Study and Simulation of a Cylindro-Parabolic Concentrator. Master Thesis.

[18] Asif, M., Muneer, T. (2013). Thermal energy: Solar technologies. Encyclopedia of Environmental Management Publication Details, 2498-2507.

[19] https://fr.wikipedia.org/wiki/Centrale thermique\#Centr ale_solaire, accessed on Feb. 10, 2016.

[20] http://en.wikipedia.org/wiki/Solar_thermal_collector, accessed on Apr. 6, 2016.

[21] Eighth Day / Photos: CNIM Archives - Themiscopyright derbi / February 2014.

[22] Verdier-Gorcias, D. (2016). Latent heat protection thermal storage integrated into a pressurized air solar receiver. $\mathrm{PhD}$. Thesis. Perpignan University, France.

[23] Bouadila, S. (2010). Latent heat energy storage study: Solar collector application. 7th Tunisian Days on Flows and Transfers, Tozeur (Tunisia) from 20 to 22 December 2010.

[24] Philip, D., Myers, D., Goswami, Y. (2016). Thermal energy storage using chloride salts and their eutectics.
Applied Thermal Engineering, 109: 889-900. https://doi.org/10.1016/j.applthermaleng.2016.07.046

[25] Jabbour, N. (2011). Integration of solar absorption systems of small powers to buildings - solar multifunction approach: Heating, ECS and cooling. PhD Thesis. Lyon Graduate School, French.

[26] Cristofari, C., Notton, G., Poggi, P., Louche, A. (2003). Influence of the flow rate and the tank stratification degree on the performances of a solar flat-plate collector. International Journal of Thermal Sciences, 42(5): 455469. https://doi.org/10.1016/S1290-0729(02)00046-7

[27] Han, Y.M., Wang, R.Z., Dai, Y.J. (2009). Thermal stratification within the water tank. Renewable and Sustainable Energy Reviews, 13(5): 1014-1026. https://doi.org/10.1016/j.rser.2008.03.001

[28] Shah, L.J. (2002). A solar combi system based on a heat storage with three internal heat exchangers. Danmarks Tekniske University, Denmark.

[29] Callen, H.B. (1985). Thermodynamics and an Introduction to Thermostatistics. 2nd Edition, John Wiley \& Sons, America.

[30] Perrot, O. (2010). Course of thermodynamics. I.U.T. of Saint-Omer Dunkirk, Department Thermal Engineering and Energy, 2010-2011, pp. 99-109.

[31] Ouargli-Saker, R. (2016). Thermodynamics Course. University of Sciences and Technology of Oran "Mohamed BOUDIAF", pp. 62-68.

[32] Sarmiento, C., Cardemil, J.M., Díaz, A.J., Barraza, R. (2018). Parametrized analysis of a carbon dioxide transcritical Rankine cycle driven by solar energy. Applied Thermal Engineering, 140: 580-592. https://doi.org/10.1016/j.applthermaleng.2018.04.097

[33] Abdelouahab, B. (2017). Thermodynamics and energy installations courses and exercises. University of Sciences and Technology of Oran, Algeria.

[34] Bensalem, Y. Thermal Machines. Course, pp. 76-97. 